\title{
Anti-HER2 antibody and ScFvEGFR-conjugated antifouling magnetic iron oxide nanoparticles for targeting and magnetic resonance imaging of breast cancer
}

\author{
This article was published in the following Dove Press journal: \\ International Journal of Nanomedicine \\ I October 2013 \\ Number of times this article has been viewed
}

\author{
Hongwei Chen ${ }^{1, *}$ \\ Liya Wang ${ }^{1,2, *}$ \\ Qiqi Yu',2 \\ Weiping Qian ${ }^{3}$ \\ Diana Tiwari' \\ Hong $\mathrm{Yi}^{4}$ \\ Andrew $Y$ Wang ${ }^{5}$ \\ Jing Huang ${ }^{1,2}$ \\ Lily Yang ${ }^{3}$ \\ Hui Mao ${ }^{1,2}$ \\ 'Department of Radiology and \\ Imaging Sciences, ${ }^{2}$ Center for Systems \\ Imaging, ${ }^{3}$ Department of Surgery, \\ Emory University School of Medicine, \\ ${ }^{4}$ Robert Apkarian Electron Microscopy \\ Core, Emory University, Atlanta, GA, \\ ${ }^{5}$ Ocean NanoTech LLC, Springdale, \\ AK, USA \\ *These authors contributed equally \\ to this work
}

Correspondence: Hui Mao

Department of Radiology and Imaging

Sciences, Emory University School of

Medicine, I84I Clifton Road, Atlanta,

GA 30329, USA

Tel +l 4047120357

Fax +I 4047125948

Email hmao@emory.edu

Lily Yang

Department of Surgery, Emory University School of Medicine, I364 Clifton Road,

Atlanta, GA 30322, USA

$\mathrm{Tel}+\mathrm{I} 4047784869$

Fax + I 404778 5II 2

Email lyang02@emory.edu

\begin{abstract}
Antifouling magnetic iron oxide nanoparticles (IONPs) coated with block copolymer poly(ethylene oxide)-block-poly( $\gamma$-methacryloxypropyltrimethoxysilane) (PEO- $b$-P $\gamma$ MPS) were investigated for improving cell targeting by reducing nonspecific uptake. Conjugation of a HER2 antibody, Herceptin ${ }^{\circledR}$, or a single chain fragment (ScFv) of antibody against epidermal growth factor receptor (ScFvEGFR) to PEO- $b$-P $\gamma$ MPS-coated IONPs resulted in HER2-targeted or EGFR-targeted IONPs (anti-HER2-IONPs or ScFvEGFR-IONPs). The anti-HER2-IONPs bound specifically to SK-BR-3, a HER2-overexpressing breast cancer cell line, but not to MDAMB-231, a HER2-underexpressing cell line. On the other hand, the ScFvEGFR-IONPs showed strong reactivity with MDA-MB-231, an EGFR-positive human breast cancer cell line, but not with MDA-MB-453, an EGFR-negative human breast cancer cell line. Transmission electron microscopy revealed internalization of the receptor-targeted nanoparticles by the targeted cancer cells. In addition, both antibody-conjugated and non-antibody-conjugated IONPs showed reduced nonspecific uptake by RAW264.7 mouse macrophages in vitro. The developed IONPs showed a long blood circulation time (serum half-life 11.6 hours) in mice and low accumulation in both the liver and spleen. At 24 hours after systemic administration of ScFvEGFR-IONPs into mice bearing EGFR-positive breast cancer 4T1 mouse mammary tumors, magnetic resonance imaging revealed signal reduction in the tumor as a result of the accumulation of the targeted IONPs.
\end{abstract}

Keywords: magnetic nanoparticles, active targeting, antifouling, breast cancer, magnetic resonance imaging

\section{Introduction}

Nanomaterials are of great interest for biomedical applications as imaging probes, ${ }^{1-4}$ phototherapy agents, ${ }^{5}$ and drug delivery carriers. ${ }^{6}$ Magnetic iron oxide nanoparticles (IONPs) functionalized with biomarker targeting ligands offer promising applications as novel and more sensitive magnetic resonance imaging (MRI) contrast enhancing agents for biomarker-specific and noninvasive detection of cancers as well as image-guided drug delivery. ${ }^{2,7,8}$ In order to achieve an effective concentration of nanoparticles in the target tissue or tumor site after systemic delivery, accumulation, retention, and eventually cellular internalization of the nanoparticles entail the targeted nanoparticles navigating from the circulation to the tissue of interest and binding to their molecular target. ${ }^{9}$ However, many types of systemically delivered nanoparticles are rapidly cleared from the circulation by the reticuloendothelial system. ${ }^{10}$ Nonspecific or "off-target" uptake by the reticuloendothelial system and macrophages results in reduced bioavailability of 
the targeting agents, a low therapeutic index, and potential toxicity to normal organs. ${ }^{11}$ For both passive tumor targeting via the enhanced permeability and retention effect in highly vascularized tumors and active tumor targeting via ligandtarget interactions, systemically administered nanoparticles are expected to have pharmacokinetic properties that maintain a high plasma concentration for a certain period of time. Therefore, reducing nonspecific binding of biomolecules and uptake of nanoparticles by the reticuloendothelial system is an important strategy for improving the sensitivity and specificity of biomarker targeted nanoparticles and for sufficient delivery of the imaging probes or therapeutic agents to the desired targets. Thus, nanoparticles with antibiofouling or "stealth" coating, which may alleviate the rapid clearance of systemically delivered targeting nanoparticles from the blood circulation and prolong the blood retention time, are desirable candidates for development of molecular imaging and drug delivery applications.

Traditionally, poly (ethylene glycol) (PEG) or poly(ethylene oxide) (PEO) molecules with an optimal molecular weight are used to modify the nanoparticle surface through different anchor groups to reduce nonspecific interaction of nanoparticles with cells. ${ }^{12-15}$ Although PEGylation has been demonstrated to be useful for preventing aggregation of nanoparticles in physiologic conditions, obtaining a sufficient PEG density on the nanoparticle surface to prevent blood opsonization may be limited by the weak affinity of anchor groups. ${ }^{16,17}$ Other surface functionalizations, such as conjugation of targeting moieties or crosslinking payload materials, may also interfere with PEGylation. Recently, polysiloxanebased block copolymers have been developed to coat and stabilize nanocrystals. ${ }^{18-21}$ These polysiloxane polymer-coated nanoparticles exhibit inept responses to macromolecules in blood and macrophage cells, likely attributable to protection of the hydrophilic layer and neutral surface from both PEO and silanol groups. In addition, these polysiloxane polymers are readily available for reacting with different functional groups through various siloxane-based molecules.

In previous work, we have shown that PEO-block-poly ( $\gamma$-methacryloxypropyltrimethoxysilane) (PEO- $b$-P $\gamma \mathrm{MPS})-$ coated magnetic IONPs enhance cancer cell targeting as well as reduce nonspecific binding compared with PEGcoated IONPs, when functionalized with the small tripeptide ligand RGD. ${ }^{21}$ Here we report the investigation of their blood retention time in mice and further development of antibiofouling PEO- $b$-P $\gamma$ MPS-coated magnetic nanocrystals for targeting and imaging of breast cancer using much larger targeting moieties, ie, the anti-HER2 monoclonal antibody (trastuzumab, Herceptin ${ }^{\circledR}$, Roche, Basel, Switzerland) or single chain antibody fragment $(\mathrm{ScFv})$ against epidermal growth factor receptor (ScFvEGFR) in order to broaden the applications of this new material with traditional and readily available antibody ligands. PEO- $b$-P $\gamma$ MPS diblock copolymer-coated IONPs are reported to have "stealth" properties and a long blood circulation time, which enables active targeting of breast cancer cells and receptor-targeted imaging of xenografted breast tumors in nude mice using MRI.

\section{Materials and methods Materials}

Sulfosuccinimidyl 6-[3'(2-pyridyldithio)-propionamido] hexanoate (Sulfo-LC-SPDP), and dithiothreitol were purchased from Pierce Biotechnology (Rockford, IL, USA). Seventy percent concentrated nitric acid, (3-aminopropyl) triethoxysilane (APTES), and all reagents for spectrophotometric determination of iron concentration, including hydroquinone, o-phenanthroline, and ammonium iron (II) sulfate hexahydrate, were purchased from Sigma-Aldrich (St Louis, MO, USA). Herceptin ${ }^{\circledR}(145 \mathrm{kDa})$ was purchased from Emory University Hospital pharmacy. ScFvEGFR (25-28 kDa) was prepared using a procedure reported previously. ${ }^{22}$ Human breast cancer cells, ie, SK-BR-3, MDA-MB-231, MCF-7, and MDA-MB-453, 4T1 mouse mammary tumor cell line was provided by Dr Fred Miller (Wayne State University, Detroit, MI, USA), along with a RAW264.7 mouse macrophage cell line were purchased from the American Type Culture Collection (ATCC, Rockville, MD, USA). SK-BR-3 or MDAMB-231 are breast cancer cells with known overexpression of HER-2 or EGFR, respectively. For comparison, MCF-7 with a low level of HER2 expression and MDA-MB-453 with a low level of EGFR expression were used as negative control cell lines. Cells were maintained as monolayer adherent cell cultures in a humidified incubator ( $95 \%$ air, $5 \% \mathrm{CO}_{2}$ ) at $37^{\circ} \mathrm{C}$ in medium supplemented with $10 \%$ heat-inactivated fetal bovine serum. The SK-BR-3, MDA-MB-231, MDA-MB-453, and 4T1 cancer cell lines and the RAW264.7 macrophage cells were kept in Roswell Park Memorial Institute 1640 medium, while the MCF-7 cancer cell were incubated in Dulbecco's Modified Eagle's Medium.

\section{Magnetic IONP synthesis and antibody conjugation}

PEO- $b$-P $\gamma$ MPS diblock copolymer-coated IONPs were synthesized using previously reported methods. ${ }^{20,21,23}$ The method for coating single core nanocrystals was similar to that reported previously with slight modification. ${ }^{20}$ 
Briefly, the purified nanocrystals $(100 \mathrm{mg}$ ) were dispersed in $10 \mathrm{~mL}$ of anhydrous tetrahydrofuran and then mixed with the newly synthesized copolymer $(1 \mathrm{~g})$ in $10 \mathrm{~mL}$ of anhydrous tetrahydrofuran. After being aged for 4 days, the mixture was added dropwise into $100 \mathrm{~mL}$ of water with gentle magnetic stirring. The tetrahydrofuran in the solution was removed by dialysis using deionized water. The resulting solution was purified using a magnetic barrier laboratory separator (SG Frantz Company Inc, Tullytown, PA, USA). This wash-resuspend cycle was repeated three times. The humanized anti-HER2 monoclonal antibody (Herceptin) and ScFvEGFR were conjugated to IONPs as breast cancer-targeting ligands. The conjugation was carried out using a two-step procedure. ${ }^{24,25}$ First, $1 \mathrm{~mL}$ of aqueous IONPs ( $1 \mathrm{mg}$ Fe) was washed thoroughly with ethanol to remove any water residue. The particles were dispersed in $0.9 \mathrm{~mL}$ of ethanol, and $1.0 \mu \mathrm{L}$ of APTES in $0.1 \mathrm{~mL}$ of ethanol was added dropwise into the suspension. The suspension of PEO- $b$-P $\gamma$ MPS diblock copolymer-coated IONPs was heated at $60^{\circ} \mathrm{C}$ for 2 hours with gentle stirring and then rinsed thoroughly with distilled water. The amine-modified particles were redispersed in $1 \mathrm{~mL}$ of phosphate-buffered saline with EDTA (20 mM sodium phosphate, $150 \mathrm{mM} \mathrm{NaCl}, 1 \mathrm{mM}$ EDTA, pH 7.5). The IONP suspension was then added with $25 \mu \mathrm{L}$ of fresh prepared $20 \mathrm{mM}$ Sulfo-LC-SPDP solution and incubated for 40 minutes at room temperature. Overnight dialysis using 12-14,000 molecular weight cutoff tubing was performed to remove excess nonreacted Sulfo-LCSPDP reagent. Next, $0.3 \mathrm{mg}$ of ScFvEGFR was washed by centrifugation using a $10 \mathrm{~K}$ Nanosep ${ }^{\circledR}$ centrifuge tube (Pall Corporation, Putnam, CT, USA). This antibody was then modified with Sulfo-LC-SPDP using the same procedure described above. Sulfo-LC-SPDP-modified antibody was treated with dithiothreitol $(50 \mathrm{mM})$, a reducing reagent, for 30 minutes followed by use of a desalting column (Zeba desalt spin columns, Pierce Biotechnology) to remove the excess dithiothreitol. Sulfhydryl-modified antibody was then mixed with Sulfo-LC-SPDP-modified IONPs and the mixture was incubated for 18 hours at $4{ }^{\circ} \mathrm{C}$, then dialyzed again using 100,000 molecular weight cutoff tubing to remove unconjugated antibody. The same method was applied to conjugate anti-HER2 antibody to IONPs, except that the resulting sample was purified using an Easysep ${ }^{\circledR}$ magnet (STEMCELL Technologies Inc, Vancouver, BC, Canada) three times to get rid of residual unconjugated HER2 antibody. The final iron concentration was determined by spectrophotometry. ${ }^{26}$ The antibody concentration was estimated by the Bradford method. ${ }^{27}$ The average hydrodynamic diameter and zeta potential of the composite nanoparticles were measured using a dynamic light scattering instrument (Malvern Zeta Sizer Nano S-90, Malvern Instruments, Malvern, UK). A transmission electron microscope (TEM, H-7500 instrument, 75 kV, Hitachi, Tokyo, Japan) was used for evaluating and visualizing the prepared nanoparticles for their core size and uniformity.

\section{Receptor-targeted cellular uptake of IONPs}

To test for receptor-mediated uptake of anti-HER2 or antiScFvEGFR-conjugated IONPs by breast cancer cells with overexpression of HER2 or EGFR, the cells were seeded in eight-well culture chamber slides overnight before incubating with the nanoparticles. Next, $100 \mathrm{nM}$ antibody-conjugated IONPs or non-antibody-conjugated IONPs in cell culture medium were added into the culture chamber, and incubation was performed at room temperature for 6 hours with gentle shaking. Afterwards, the cells were washed twice with phosphate-buffered saline to remove excess particles and fixed with 4\% paraformaldehyde. Prussian blue staining was used to determine the presence of iron in all the cells followed by counterstaining with Nuclear Fast red solution. The results of Prussian blue staining were assessed using a light microscope. For HER2 or ScFvEGFR inhibition experiments, before incubating with anti-HER2 or ScFvEGFRIONPs, the cells were treated with 100 times excess of free HER2 or ScFvEGFR (molar ratio) for one hour followed by three washes with phosphate-buffered saline. For testing nonspecific uptake, anti-HER2-IONPs, ScFvEGFR-IONPs, and nonconjugated IONPs were incubated with macrophages (RAW264.7). After each well was exposed to a $0.1 \mathrm{mg} / \mathrm{mL}$ IONP in Hanks solution for one hour at $37^{\circ} \mathrm{C}$, the cells were washed with phosphate-buffered saline and then fixed for 20 minutes with $0.5 \mathrm{~mL}$ of $4 \%$ paraformaldehyde. Subsequently, the cells were stained with Prussian blue and Nuclear Fast red, and then mounted to be visualized.

\section{Electron microscopy of uptake of ScFvEGFR-conjugated IONPs}

After 8 hours of incubation $\left(95 \%\right.$ air, $\left.5 \% \mathrm{CO}_{2}, 37^{\circ} \mathrm{C}\right)$ with ScFvEGFR-conjugated IONPs, MDA-MB-231 cells were fixed with $2.5 \%$ glutaraldehyde in $0.1 \mathrm{M}$ cacodylate buffer (pH 7.2) and embedded in epoxy resin. Monolayer cells on the surface of the resin block were then sectioned into $70 \mathrm{~nm}$ ultrathin sections and imaged without contrasting stain on a TEM (JEM-1400, JEOL, Tokyo, Japan) equipped with a Gatan Orius 832 charge-coupled device (CCD). 


\section{Serum half-life and biodistribution of IONPs in mice}

All animal experiments in this work were approved by the Institutional Animal Use and Care Committee at Emory University. The blood circulation time and organ biodistribution of PEO- $b$-P $\gamma$ MPS diblock copolymer-coated IONPs in mice were determined by measuring iron concentrations in the serum and tissue samples. ${ }^{28} \mathrm{BALB} / \mathrm{c}$ mice aged 4-6 weeks ( $n=4$ /group) were injected intravenously via the tail vein with PEO- $b$-P $\gamma$ MPS diblock copolymer-coated IONPs (10 mg Fe/kg of body weight) in phosphate-buffered saline solution. At different time points, ie, 0.25, 1, 2, 4, 8, 24 , and 48 hours after administering the nanoparticles, the animals were euthanized. Blood samples were collected by terminal heart puncture and centrifuged for 10 minutes at $5,000 \mathrm{rpm}$ to separate the plasma. Tissue samples of liver, spleen, kidney, lung, brain, and muscle were collected, followed by weighing and freeze drying. To determine the iron concentrations in the sera or specimens, $100 \mu \mathrm{L}$ of serum or weighted organ tissue samples were digested in $1 \mathrm{~mL}$ of nitric acid ( $2 \mathrm{~mL}$ for the liver). Iron concentrations in mouse blood and organs as well as in the IONP solution were determined colorimetrically using 1,10-phenanthroline. ${ }^{26}$ A calibration curve was created using standard solutions containing the iron-1,10-phenanthroline complex in water with iron concentrations ranging from $0.4 \mu \mathrm{g} / \mathrm{mL}$ to $4 \mu \mathrm{g} / \mathrm{mL}$. Nitric acid solutions of decomposed serum $(400 \mu \mathrm{L})$ and decomposed organ tissue $(200 \mu \mathrm{L})$ were used to measure the iron mass. Absorption spectra were obtained using a scanning spectrophotometer (UV-2401PC, Shimadzu, Kyoto, Japan) with a slit width of $1.0 \mathrm{~nm}$.

\section{MRI of tumor-bearing mice administered IONPs}

The mouse mammary tumor model was generated as described elsewhere. ${ }^{29}$ Briefly, $1 \times 10^{7}$ of $4 \mathrm{~T} 1$ mouse mammary tumor cells with EGFR overexpression were inoculated subcutaneously on the upper back of female Balb/c mice aged 4-6 weeks. Tumors were allowed to grow for 10-14 days after inoculation before imaging experiments. Tumor-bearing mice were scanned using a 4.7 Tesla horizontal bore $(33 \mathrm{~cm}$ ) MRI scanner (Unity INOVA, Varian, Palo Alto, CA, USA). The mice were placed in a custom-built volume coil ( $5 \mathrm{~cm}$ inner diameter and $8 \mathrm{~cm}$ long) and anesthetized using $2 \%$ isoflurane delivered via a mask throughout the MRI experiments. The animals were kept warm in the scanner using a circulating water blanket. A set of survey images was obtained using a T2-weighted fast spin echo imaging sequence with a repetition time of $5,000 \mathrm{msec}$ and an echo time of $82 \mathrm{msec}$. A multi-echo T2-weighted fast spin echo sequence was followed by high-resolution images of a selected field of view covering the full extent of the tumor, with a $\mathrm{T} 2$-weighted fast spin echo sequence having a repetition time of 5,000 msec, a multiple effective echo time of $20,40,60$, and $80 \mathrm{msec}$, and a $256 \times 256$ matrix to obtain $\mathrm{T} 2$ relaxometry of the whole mouse. Typically, a field of view of $40 \times 70 \mathrm{~mm}$, a slice thickness of $1 \mathrm{~mm}$, and no gap were used.

The mice were imaged before and 24 hours after being injected with ScFvEGFR-IONPs or non-targeted IONPs (10 mg Fe/kg mouse body weight) in phosphate-buffered saline $(100 \mu \mathrm{L})$ through the tail vein. All pre-contrast and post-contrast MRI images were compared to evaluate enhancement by the target-specific contrast agent. ImageJ (National Institutes of Health, Bethesda, MD, USA, http://imagej.nih.gov/ij/, 1997-2011) was used to analyze the magnetic resonance images quantitatively. The regions of interest were selected by tracing the tumor and other organs. The outlines of all regions of interest were defined by two experienced readers based on magnetic resonance images. The regions of interest were used to evaluate and quantify the contrast agent-induced signal or T2 value changes in the tumor and other organs. The averaged signal intensity of the regions of interest was then analyzed quantitatively using ImageJ for comparing the signal intensity before and after injection of ScFvEGFR-IONPs.

\section{Histologic analysis}

The mice were sacrificed following MRI at 24 hours after injection of the contrast agent. Tumors and major organs were collected. The selected tissue blocks were embedded in Tissue-Tek OCT compound (Sakura Finetek Inc., Torrance, CA, USA) and frozen immediately using liquid nitrogen. The frozen tissue blocks were sectioned into slices $5 \mu \mathrm{m}$ thick and examined by Prussian blue staining to confirm the presence of IONPs in the tissue sections. After counterstaining with Nuclear Fast red, the slides were examined under light microscopy.

\section{Results and discussion Functionalization of PEO-b-PyMPS-coated IONPs with antibodies}

PEO- $b$-P $\gamma$ MPS diblock copolymer-coated IONPs (core size $10 \mathrm{~nm}$ ) were made using a previously developed method, ${ }^{20,30}$ and amine groups with further silylation of 
APTES were introduced. Functionalization of PEO- $b$ P $\gamma$ MPS-coated IONPs with targeting ligands was performed using a covalent conjugation method, as shown in Figure 1. Both the aminated IONPs and antibodies (ie, anti-HER2, ScFvEGFR) were first activated by Sulfo-LC-SPDP, which is a commercially available and widely used bifunctional crosslinker for bioconjugation. Free thiol groups on antibodies were generated by further reduction with dithiothreitol, and then conjugated with pyridyldithiol-activated IONPs. After conjugation, the overall hydrodynamic size increased from $23 \mathrm{~nm}$ to $35 \mathrm{~nm}$. The zeta potential of the resulting nanoparticles was reduced from $-9.7 \mathrm{mV}$ to $-4.2 \mathrm{mV}$. The conjugated nanoparticles retained their morphologic features, as demonstrated by TEM (Figure S1A). The Bradford assay was applied to quantify the amount of antibody on the particle surface (Figure S1B). Based on the Bradford calibration curve, it was estimated that approximately $3-5$ anti-HER2 antibodies or approximately $28 \mathrm{ScFvEGFR} \mathrm{molecules} \mathrm{had}$ been conjugated to each IONP.

\section{Specificity binding and targeting of HER 2 by anti-HER2-IONPs}

To confirm the specificity of HER2 targeting, anti-HER2IONP conjugates were incubated with HER2-overexpressing SK-BR-3 cells, with HER2-underexpressing MCF-7 and MDA-MB-231 cancer cell lines used as controls. ${ }^{31}$ Strong uptake of anti-HER2-IONPs by HER2-positive cells was demonstrated on Prussian blue staining, as shown in Figure 2A. Inhibiting the HER2 receptor with 100 times excess of free HER2 antibody effectively reduced the amount of blue staining (Figure 2B), ${ }^{24}$ suggesting that uptake of targeted IONPs is specifically mediated by HER-2 receptors on the cancer cells. Additionally, Prussian blue staining was negative in MCF-7 and MDA-MB-231 cancer cell lines after treatment with anti-HER2-IONPs, as shown in Figure 2C and D, further

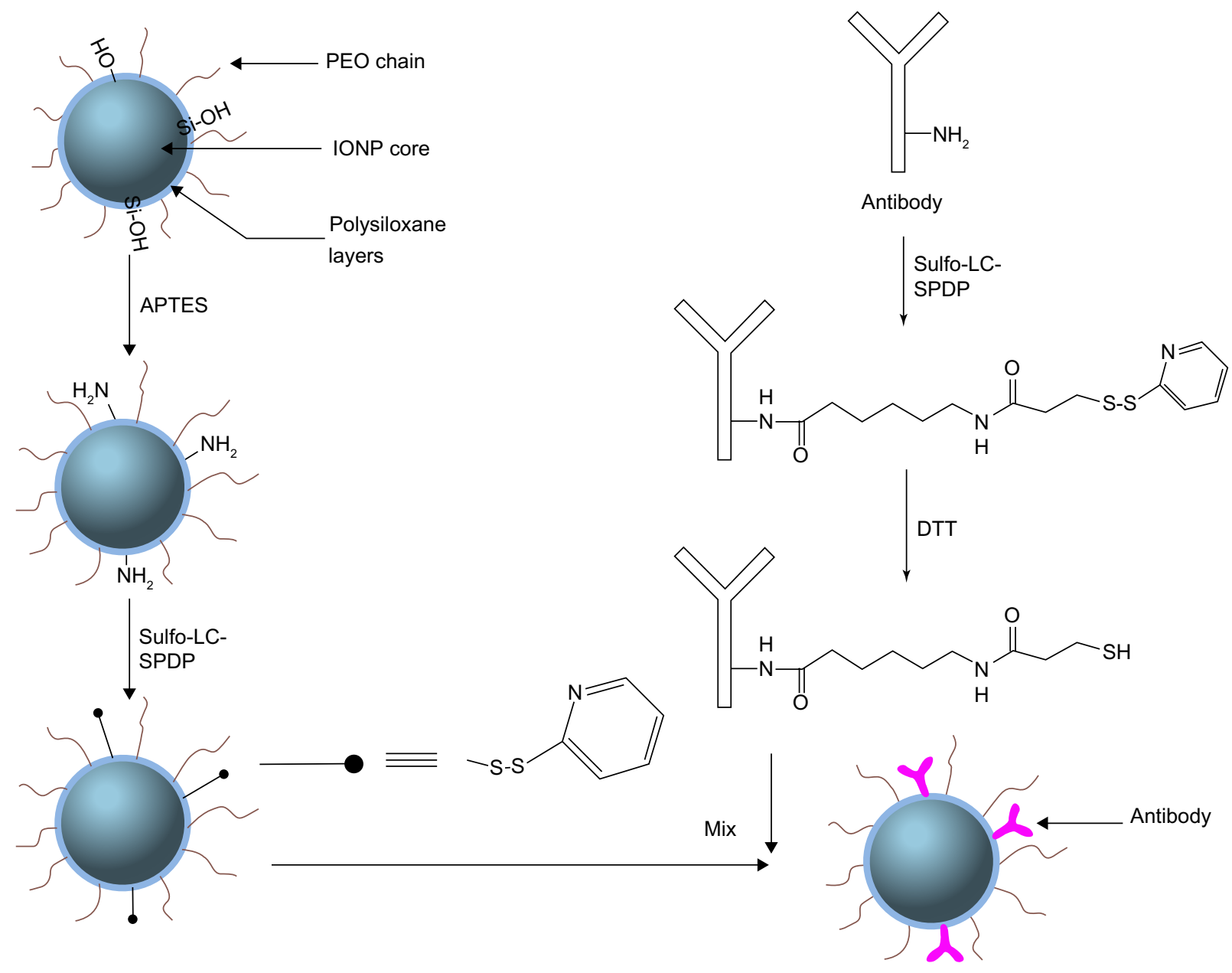

Figure I Antibody conjugation of nanoparticles with polysiloxane copolymer coating.

Abbreviations: PEO, poly(ethylene oxide); IONPs, iron oxide nanoparticles; APTES, (3-aminopropyl) triethoxysilane; Sulfo-LC-SPDP, Sulfosuccinimidyl 6-[3'(2-pyridyldithio)propionamido] hexanoate; DTT, dithiothreitol. 


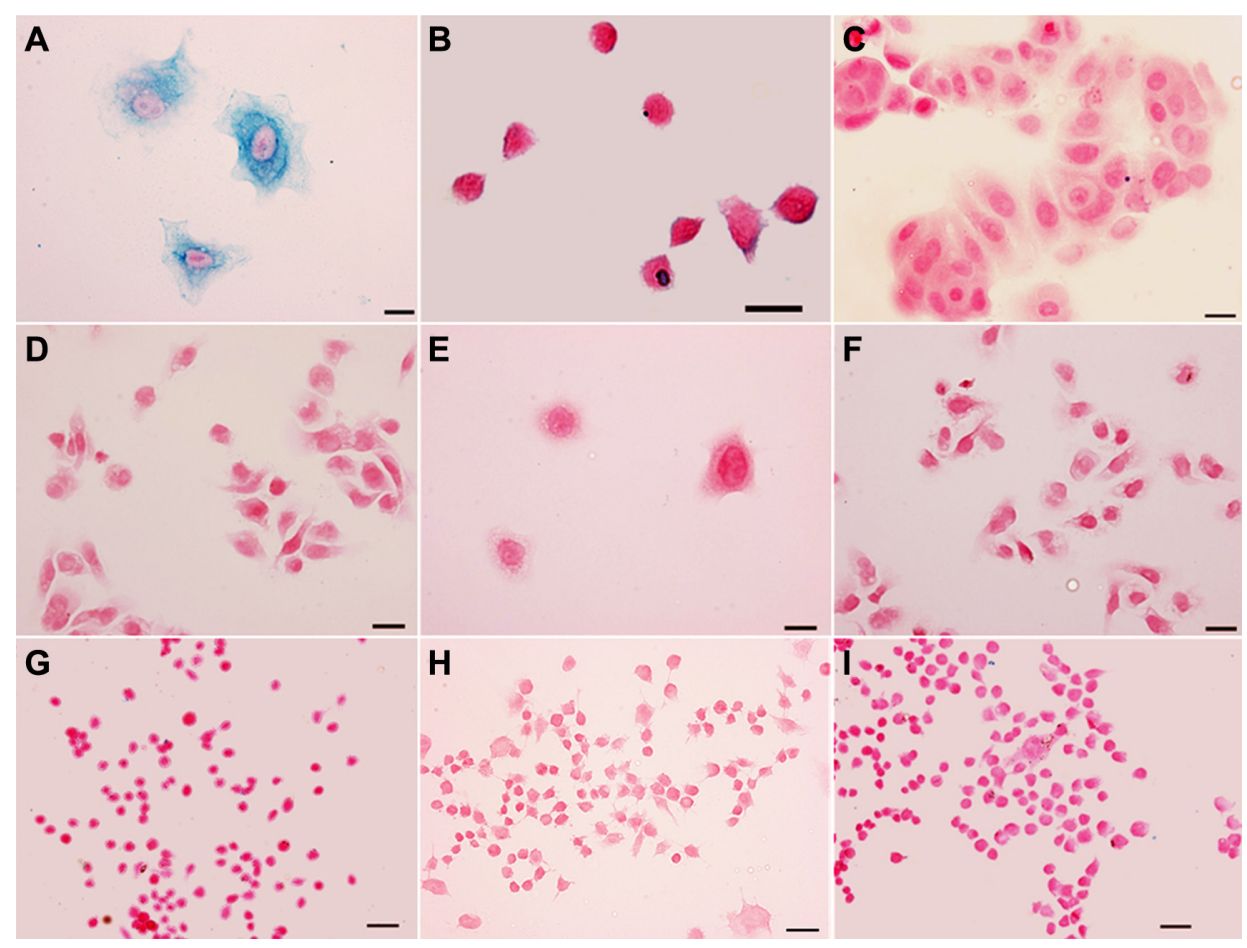

Figure 2 Prussian blue staining of HER2-positive SK-BR-3 cancer cells (A), 100 times free pre-HER2 blocked SK-BR-3 cancer cells (B), negative MCF-7 and MDA-MB-23। cancer cells (C and D) treated with anti-HER2-IONPs, and both SK-BR-3 and MDA-MB-23I treated with nonconjugated IONPs (E and F). Prussian blue stained images of a macrophage cell line, RAW264.7, after treatment with anti-HER2-IONPs, ScFvEGFR-IONPs and nonconjugated IONPs (G-I). Cells were incubated with IONPs with a concentration of $0.1 \mathrm{mg} / \mathrm{mL} \mathrm{Fe}$ in an incubator for one hour. Scale bar is $50 \mu \mathrm{m}$.

Abbreviations: IONPs, iron oxide nanoparticles; ScFvEGFR, single chain fragment of antibody against epidermal growth factor receptor.

confirming the binding specificity of anti-HER2-IONPs. In contrast, when treated with nonconjugated IONPs under the same conditions, Prussian blue staining was negative in all cancer cells (Figure 2E and F), suggesting reduced nonspecific binding in the condition when active targeting was taking place. To test further if the bioconjugation process itself or exposed ligands may cause the nonspecific uptake by macrophages, ${ }^{32}$ Prussian blue staining was carried out to detect the presence of IONPs in macrophages after incubation of the cells with the targeted IONPs. As shown in Figure 2G and H, HER2 antibody-conjugated IONPs and ScFvEGFR-conjugated IONPs did not show any cellular uptake by macrophages after one hour of incubation, similar to the PEO- $b$-P $\gamma$ MPS copolymer-coated nontargeted IONPs (Figure 2I). This result suggests that antibody modification does not significantly increase nonspecific binding by cancer cells or uptake by macrophages.

Differences in the expression of cellular receptors between normal and tumor cells represent a great opportunity for targeting nanoparticles to cancer cells. Using antibodies as tumor-targeting ligands for magnetic or photosensitive nanoparticles has been studied extensively in vitro and in vivo in the area of cancer imaging. ${ }^{9,33,34}$ Given that HER2, a well known antibody against the HER $2 /$ neu receptor overexpressed in breast cancer cells, has been widely used in the clinic for treating patients with HER2 overexpression, developing a potential clinically applicable HER2-targeting nanoparticle imaging probe and drug delivery platform has been an active research area. ${ }^{35-40}$ Previous investigations have shown the efficiency of bioconjugation of the HER2 antibody to nanoparticles, including iron oxide nanoparticles and $^{41-43}$ dumb bell-like Au-Fe ${ }_{3} \mathrm{O}_{4}$ nanoparticles for specific targeting of breast cancer cells and targeted delivery. ${ }^{44}$ Our development of HER2-targeted PEO- $b$-P $\gamma$ MPS copolymercoated IONPs should provide improved HER2 targeting with reduced nonspecific uptake by macrophages and the reticuloendothelial system as well as a prolonged blood circulation time.

\section{Specific binding and targeting of EGFR by ScFvEGFR-IONPs}

EGFR serves as an important anticancer therapeutic and imaging target because of its overexpression in a variety of cancers. Here we employed ScFvEGFR as another approach to evaluate further the feasibility of delivery of the receptortargeted nanoparticle into tumor cells. ScFvEGFR are the 
variable region of antibody against EGFR, which retains the specificity of the original immunoglobulin and avoids Fc-mediated uptake of antibody-conjugated magnetic nanoparticles by phagocytic cells. Recent work has shown that ScFvEGFR could be used to target EGFR, resulting in molecular imaging of EGFR-overexpressing tumors with excellent tumor-to-background contrast. ${ }^{22,45}$ In the current work, cell lines with high-level or low-level expression of EGFR were used to test specific targeting of ScFvEGFRIONPs. Figure 3 shows Prussian blue staining of IONPs in different cells treated with ScFvEGFR-IONPs, indicating significant uptake of ScFvEGFR-conjugated IONP in the EGFRpositive MDA-MB-231 cell line (Figure 3A). As described above, the binding of EGFR-targeted nanoparticles could be extensively inhibited by an excess amount of free ScFvEGFR (Figure 3B). ${ }^{24}$ In comparison, there was no cellular uptake observed in two cell lines (MCF-7 and MDA-MB-453) with no or low EGFR expression (Figure 3C and D). As a control, the PEO- $b$-P $\gamma$ MPS copolymer-coated IONPs without targeting ligands showed no uptake in any of the positive or negative cell lines (Figure $3 \mathrm{E}$ and F).

To examine further the cellular uptake of EGFR-targeted IONPs, TEM was used to visualize nanoparticles in the cellular compartments, given the high electron density of metal nanoparticles. ${ }^{17,42,46}$ Figure 4 shows TEM imaging of MDAMB-231 cells treated with ScFvEGFR-conjugated IONPs that shows the cellular uptake of ScFvEGFR-conjugated nanoparticles and successful receptor-mediated endocytosis of the targeted nanoparticles. Major cellular organelles, such as the nucleus, mitochondria, Golgi apparatus, and endoplasmic reticulum are clearly observed in the TEM images. The overall view of Figure 4A shows that most of the ScFvEGFR-conjugated IONPs are located in multivesicular bodies and secondary lysosomes throughout the cytoplasm, with excellent preservation of membrane structures. No particles are observed in the cytoplasm. At higher magnification of a region in Figure 4A, multivesicular bodies loaded with ScFvEGFR-IONPs can be visualized in greater detail (Figure 4B-D). EGFR is a single membrane spanning protein with an extracellular amino terminus and intracellular carboxyl terminus. Upon ligand binding, EGFRs are activated, which results in rapid and efficient internalization of the receptors via endocytosis. The resulting endocytic vesicles round and pinch off, and are then carried into cells for processing, disassembly, or recycling. ${ }^{22}$ The results from TEM experiments confirm that antibody-conjugated IONPs could be incorporated into cells via this receptor-mediated endocytosis.

\section{Serum half-time and biodistribution of PEO-b-PyMPS-coated IONPs}

\section{in normal mice}

The blood retention time and biodistribution of PEO- $b$ P $\gamma$ MPS-coated IONPs was investigated by measuring

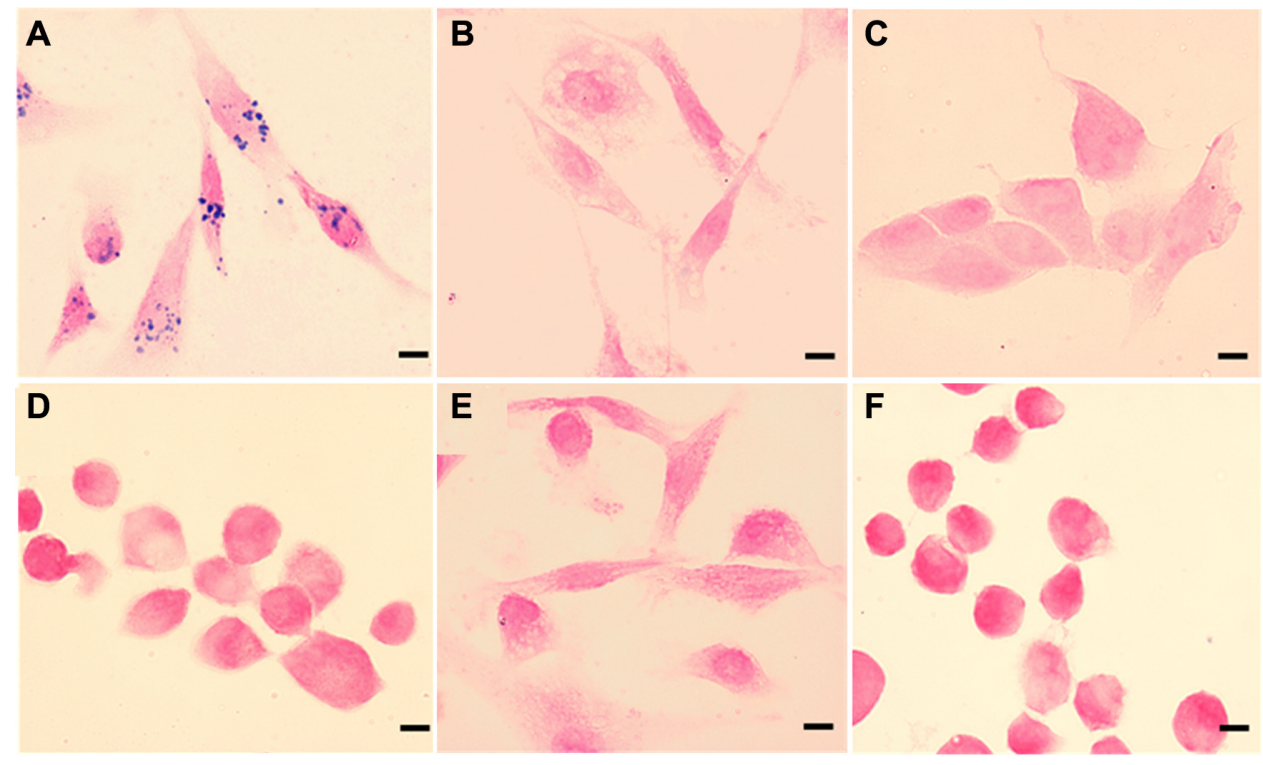

Figure 3 Prussian blue staining of MDA-MB-23I cancer cells bound with ScFvEGFR-IONPs (A), 100 times free ScFvEGFR inhibited the binding of EGFR-positive MDAMB-23I cancer cells (B), negative MCF-7 and MDA-MB-453 cancer cells (C and D) treated with ScFvEGFR-IONPs, and MDA-MB-23I, and MDA-MB-453 treated with nonconjugated IONPs ( $E$ and $\mathbf{F}$ ). Scale bar is $10 \mu \mathrm{m}$.

Abbreviations: IONPs, iron oxide nanoparticles; ScFvEGFR, single chain fragment of antibody against epidermal growth factor receptor. 


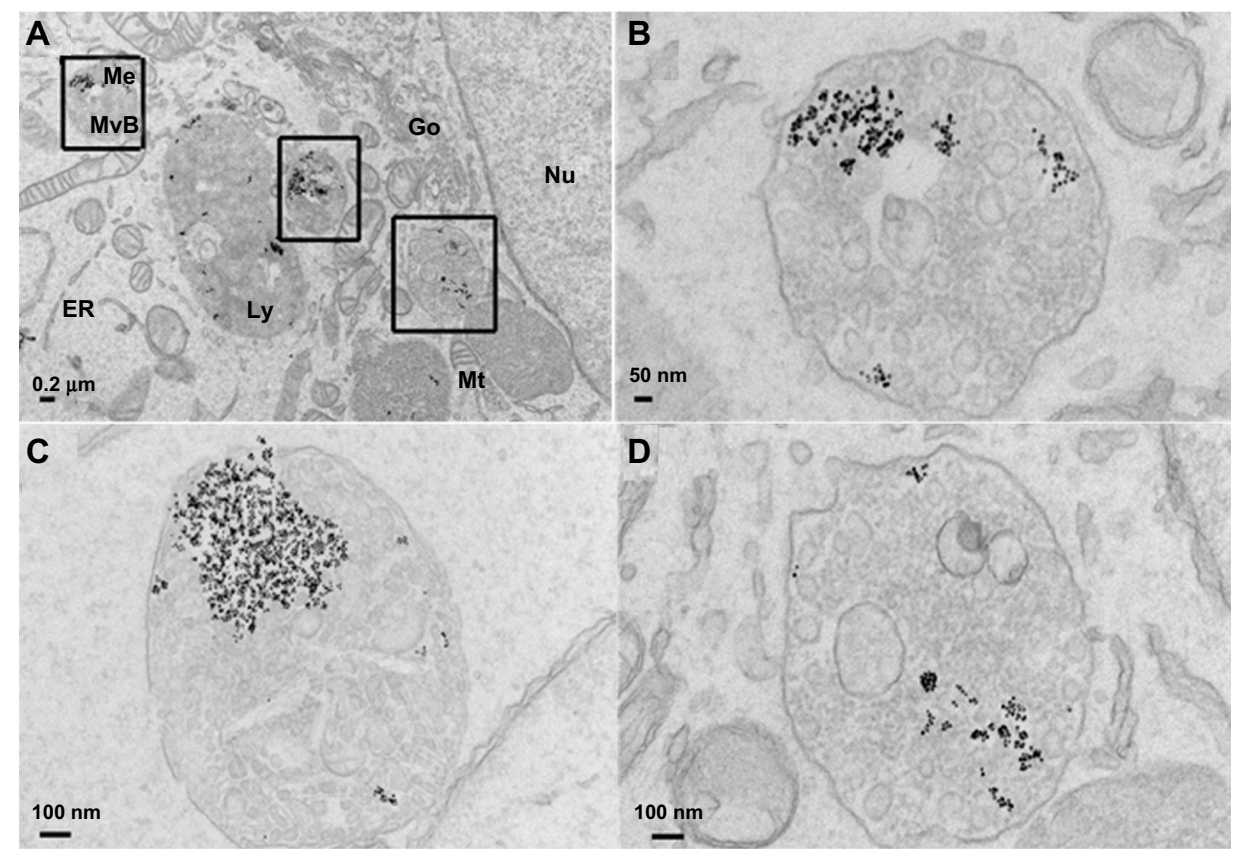

Figure 4 Transmission electronic microscopic images of uptake of ScFvEGFR-IONPs by MDA-MB-23I cancer cells (A). Panel (B-D) shows the high magnification image in the square from panel $(\mathbf{A})$.

Abbreviations: IONPs, iron oxide nanoparticles; ScFvEGFR, single chain fragment of antibody against epidermal growth factor receptor; Nu, nucleus; Mt, mitochondria; Go, Golgi apparatus; ER, endoplasmic reticulum; MvB, multivesicular bodies; Me, membrane structures; Ly, lysosome.

the iron concentrations in serum and selected organs at various time points after intravenous injection of a dose of $10 \mathrm{mg} \mathrm{Fe} / \mathrm{kg}$ (mouse body weight) of IONPs in mice ( $\mathrm{n}=4$ per time point). Iron concentration was determined by spectrophotometry (Figure S2). Figure 5A shows a plot of the time-dependent change in mean serum iron concentration. The mean iron concentration in mouse serum at 15 minutes after injection of IONPs was $0.323 \pm 0.039 \mathrm{mg} \mathrm{Fe} / \mathrm{g}$, which was 6.9 times higher than that $(0.047 \pm 0.009 \mathrm{mg} \mathrm{Fe} / \mathrm{g})$ in the control mice not receiving IONPs, followed by gradual clearance of nanoparticles from the blood. Forty-eight hours after injection of PEO- $b$-P $\gamma$ MPS-coated IONPs, the iron concentration in serum approached the background level of $0.059 \pm 0.014 \mathrm{mg} \mathrm{Fe} / \mathrm{g}$. By fitting iron concentrations obtained at different time points to a monoexponential decay model, an estimated serum half-life $\left(\mathrm{t}_{1 / 2}\right)$ of 11.6 hours $\left(R^{2}=0.993\right)$ was obtained for PEO- $b$-P $\gamma$ MPS diblock copolymer-coated IONPs. This blood half-time is in the range generally considered optimal for nanoparticles to reach and accumulate in the target tumor tissue. ${ }^{47}$

This blood circulation time is comparable with the IONP organ distribution, in which the same analytical method was used to determine iron concentrations in the selected organs at different time points after injection of PEO- $b$-P $\gamma$ MPS-coated IONPs. Although the endogenous iron content is high in the liver and spleen, the current method is still sensitive enough to detect the change in iron content over time in these organs after intravenous injection of IONPs at dosage of $10 \mathrm{mg} \mathrm{Fe} / \mathrm{kg}$ body weight. The biodistribution data shown in Figure 5B indicate that the iron concentrations in the liver, spleen, and lung increased initially and then decreased after peaking at about 8 hours. Twenty-four hours after injection, iron concentrations in the liver, spleen, and lung reduced further to levels close to those in normal controls, eg, the mean iron concentration in the spleen was $6.5 \pm 1.0 \mathrm{mg} \mathrm{Fe} / \mathrm{g}$ and $6.8 \pm 1.0 \mathrm{mg} \mathrm{Fe} / \mathrm{g}$ dry tissue for the experimental and control groups, respectively. Most IONPs, including commercially available Feridex, take at least several weeks to be cleared out of the body from the liver and spleen. The observation of a rapid reduction in liver iron 24 hours post injection of PEO- $b$-P $\gamma$ MPS diblock copolymer-coated IONPs suggests that these PEO- $b$-P $\gamma$ MPS diblock copolymer-coated IONPs have a lower level of uptake by the reticuloendothelial system. The data were further analyzed as percentages of injection dose after subtraction of the background iron level, as shown in Figure S3. After 24 hours, $42 \%$ of the IONP injection dose was still circulating in the blood as calculated from the data in Figure 5A, assuming that the total blood weight is about $7.8 \%$ of the mouse body weight. ${ }^{48}$ While about $34 \%$ of the injection dose was detected in the liver, small amounts of IONPs were also detected in the kidney (6.1\% injection dose), the lungs (3.4\% injection dose), and the brain (3.1\% 

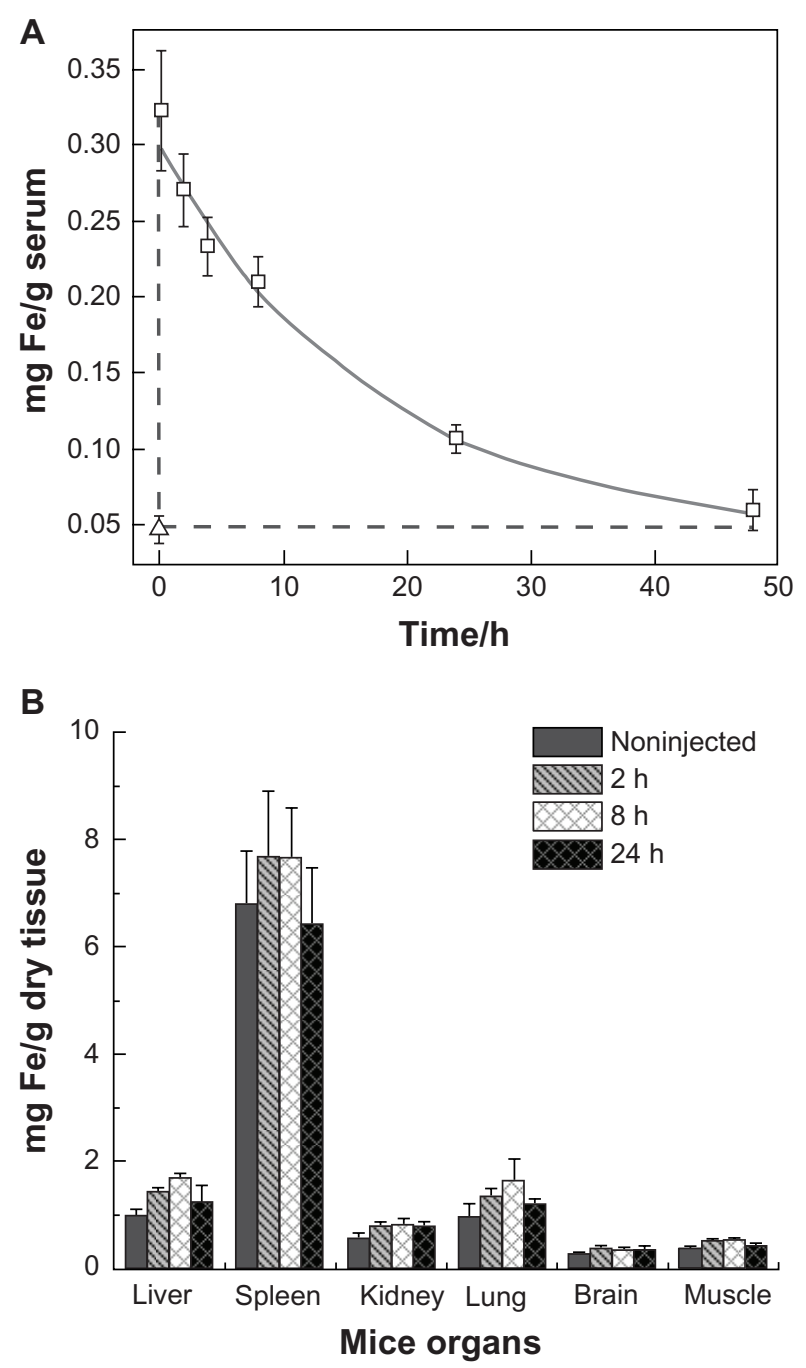

Figure 5 (A) Serum half-life of nanoparticles after tail vein injection of $10 \mathrm{mg} \mathrm{Fe} / \mathrm{kg}$ of mouse body weight (open squares), where iron concentration was measured by spectrophotometry. Triangle represents serum iron concentration in noninjected control mice. The error bar is the standard deviation with four mice in each time point. (B) Biodistribution of PEO-b-PyMPS-coated IONPs in the major organs of $\mathrm{BALB} / \mathrm{c}$ mice, including liver, spleen, kidney, lung, brain, and muscle. The data were recorded from the whole organ taken at indicated time points after tail vein injection and were determined by spectrophotometry. Each group contains four mice, and the error bar is the standard deviation.

Abbreviations: IONPs, iron oxide nanoparticles; PEO-b-PyMPS, poly(ethylene oxide)-block-poly( $\gamma$-methacryloxypropyltrimethoxysilane); h, hours.

injection dose) at 24 hours post injection. It is worth noting that the percent injection dose value is negative in the spleen, which is likely due to low accumulation of administered PEO- $b$-P $\gamma$ MPS diblock copolymer-coated IONPs, so that it is within the variation of the averaged spleen iron concentration obtained from different animals large variation in iron concentrations in the spleen as well as in the liver as measured by chemical analysis of tissue samples can be attributed to the significantly higher basal iron concentrations of the liver and spleen (eg, $6.8 \pm 1.0 \mathrm{mg} \mathrm{Fe} / \mathrm{g}$ dry tissue). Taken together, our in vivo biodistribution data show reduced uptake by immune cells that primarily exist in the liver and spleen. The results of this study further validate the antibiofouling properties of PEO- $b$-P $\gamma$ MPS diblock copolymer-coated IONPs. ${ }^{21}$ While the reticuloendothelial system provides a major route for nanoparticle clearance, other mechanisms and organs may also be involved. ${ }^{49}$ Nevertheless, further investigations on the clearance of these long circulating and antifouling nanoparticles is necessary in the future.

\section{EGFR-targeted MRI of a breast tumor mouse model}

After confirming receptor-specific targeting in vitro, an in vivo study was carried out to compare the differences between targeting and nontargeting nanoparticles. MRI was performed in the mice bearing subcutaneous tumors grown from 4T1 cells before and 24 hours after intravenous injection of EGFR-targeted ScFvEGFR-IONPs or nontargeted IONPs as control (10 mg Fe/kg mouse body weight). Figure 6 shows an example of T2-weighted magnetic resonance images of selected axial slices from a mouse bearing a 4T1 tumor recorded before and 24 hours after administering ScFvEGFRIONPs. A significant signal drop can be found in various areas of the tumor in comparison with images from the tumor before injection of IONPs. The change in MRI signals from the region suggests accumulation of magnetic nanoparticles which cause substantial reduction in $\mathrm{T} 2$ relaxation time and susceptibility effect, leading to T2-weighted MRI contrast. At 24 hours after intravenous injection of ScFvEGFR-IONPs, the averaged signal intensity of the tumor dropped $28 \%$ comparing to pre-injection $(P<0.005)$. In comparison, the MRI signal change was not significant in the tumors of mice injected with nonconjugated IONPs ( $P>0.05$, Figure 6E). The presence of ScFvEGFR-IONPs in tumor tissue was further confirmed by Prussian blue staining of tumor tissue slices (Figure 6F). Consistent with the MRI images, there was no obvious Prussian blue staining in tumor tissue from the control mice (Figure 6G). It should be noted that the current in vivo MRI experiment was done using a rather small sample size, limiting further quantitative analysis and comparison of different IONPs. The example shown in Figure 6 demonstrates the feasibility of using ScFvEGFRIONPs for MRI contrast enhancement of targeted tumors with histologic validations.

It is proposed that targeted nanoparticles are facilitated by both a "passive" mechanism and an "active" mechanism to accumulate at the tumor site. ${ }^{50}$ In the passive mode, nanoparticles are accumulated and retained in the tumor interstitial space mainly via the enhanced permeability and 


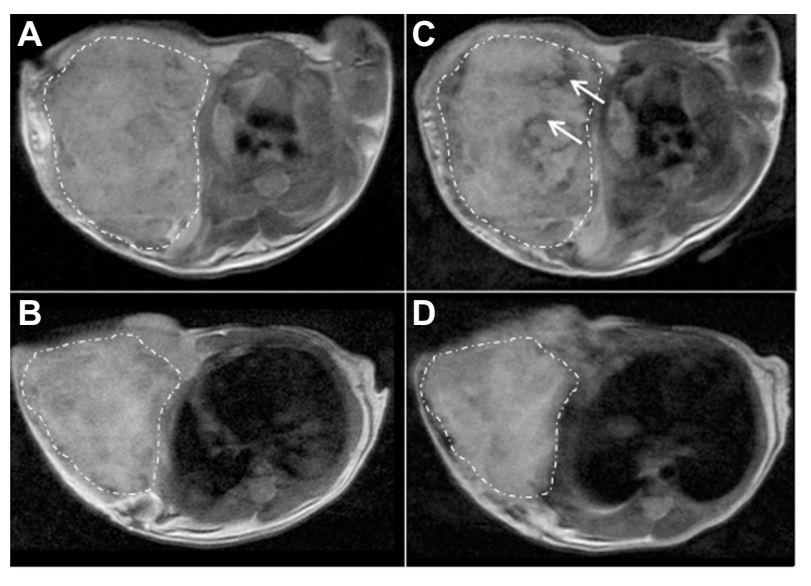

E
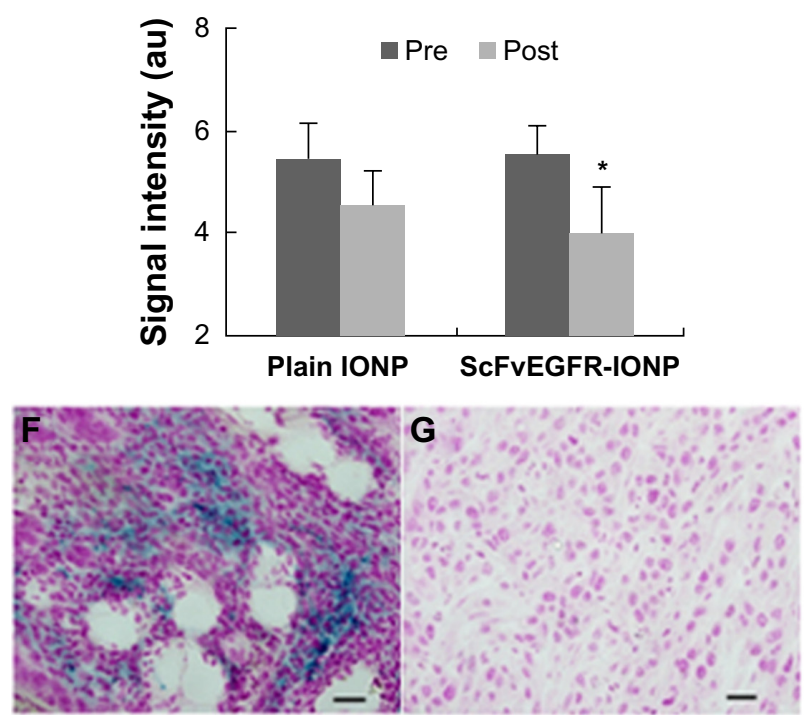

Figure 6 Selected axial sections of T2-weighted magnetic resonance images of mice bearing 4TI mammary tumors before injection ( $\mathbf{A}$ and $\mathbf{B}$ ), and 24 hours after intravenous injection of ScFvEGFR-IONPs (C) and IONPs without targeting ligands (D). Tumor margins are traced with dotted lines. The regions with dropped signal due to accumulation of ScFvEGFR-IONPs are indicated by arrows. The averaged signal intensity of tumors pre-injection and post-injection of IONPs was plotted (E). $* P<0.05$. The presence of IONPs in the tumors was confirmed by Prussian blue staining of tumor tissues obtained 24 hours after injection of ScFvEGFR-conjugated IONPs (F) and plain IONPs (G)

Abbreviations: IONPs, iron oxide nanoparticles; ScFvEGFR, single chain fragment of antibody against epidermal growth factor receptor.

retention effect. ${ }^{51}$ In the active mode, targeting ligands can recognize specific receptors on tumor blood vessels and tumor cell surface followed by receptor-mediated endocytosis and nanoparticle internalization. Although recent studies have shown that there is still considerable debate about the relative contributions of such active and passive targeting mechanisms, the low targeting efficiency might be mainly caused by the fact that most (up to $90 \%$ ) of the injected nanoparticles are trapped by the reticuloendothelial system or taken up nonspecifically by macrophages within 24 hours of systemic administration. ${ }^{17}$ Targeted
IONPs with antifouling "stealth" coating may facilitate active targeting by reducing nonspecific uptake and prolonging blood circulation time, both of which can benefit passive targeting for more effective delivery of IONPs into tumor tissue.

\section{Conclusion}

Magnetic iron oxide nanoparticles coated with an antibiofouling "stealth" polysiloxane-containing PEO- $b$-P $\gamma$ MPS copolymer have a long blood circulation time with reduced nonspecific uptake by the reticuloendothelial system and macrophages. With covalent conjugation of the antibody against HER2 or ScFvEGFR to PEO- $b$-P $\gamma$ MPS-coated IONPs, HER2-targeted or EGFR-targeted IONPs are capable of efficiently targeting breast cancer cells that overexpress HER 2 or EGFR, respectively. In contrast, nontargeted IONPs do not show cellular uptake in these cell lines. Furthermore, receptor-specific cell binding and internalization can be effectively inhibited by pretreatment with excess amounts of free anti-HER2 antibody or ScFvEGFR. With the "stealth" properties demonstrated in this study, these IONPs facilitate effective targeting of cancer cells. Such antibiofouling polymer-coated magnetic nanoparticles with their biomarkertargeting ability are promising candidates for the development of molecular imaging probes and image-assisted drug delivery carriers.

\section{Acknowledgment}

This work is supported in parts by the grant from the National Cancer Institute program project in vivo Cellular and Molecular Imaging Center (P50CA128301-01A10003 to HM and LY), Cancer Nanotechnology Platform Project grant (U01CA151810-02 to HM and LY) and a research grant (R01CA154846-02 to HM and LY) from the National Cancer Institute.

\section{Disclosure}

The authors report no conflicts of interest in this work.

\section{References}

1. Weissleder R. Molecular imaging in cancer. Science. 2006;312(5777): 1168-1171.

2. Kim J, Piao Y, Hyeon T. Multifunctional nanostructured materials for multimodal imaging, and simultaneous imaging and therapy. Chem Soc Rev. 2009;38(2):372-390.

3. Joshi A, Bardhan R, Chen WX, et al. Tracking of multimodal therapeutic nanocomplexes targeting breast cancer in vivo. Nano Lett. 2010; 10(12):4920-4928.

4. Park K, Lee S, Kang E, Kim K, Choi K, Kwon IC. New generation of multifunctional nanoparticles for cancer imaging and therapy. Adv Funct Mater. 2009;19(10):1553-1566. 
5. Kuo WS, Chang CN, Chang YT, et al. Gold nanorods in photodynamic therapy, as hyperthermia agents, and in near-infrared optical imaging. Angew Chem Int Ed Engl. 2010;49(15):2711-2715.

6. Chow EK, Zhang XQ, Chen M, et al. Nanodiamond therapeutic delivery agents mediate enhanced chemoresistant tumor treatment. Sci Transl Med. 2011;3(73):73ra21.

7. Kim J, Lee JE, Lee SH, et al. Designed fabrication of a multifunctional polymer nanomedical platform for simultaneous cancertargeted imaging and magnetically guided drug delivery. Adv Mater. 2008;20(3):478-483.

8. Jun YW, Lee JH, Cheon J. Chemical design of nanoparticle probes for high-performance magnetic resonance imaging. Angew Chem Int Ed Engl. 2008;47(28):5122-5135.

9. Ruoslahti E, Bhatia SN, Sailor MJ. Targeting of drugs and nanoparticles to tumors. J Cell Biol. 2010;188(6):759-768.

10. Sarimollaoglu M, Nedosekin DA, Galanzha EI, Zharov VP. In vivo real-time monitoring of nanoparticle clearance rate from blood circulation using high speed flow cytometry. Proc SPIE. 2012;8427.

11. Nie SM. Understanding and overcoming major barriers in cancer nanomedicine. Nanomedicine. 2010;5(4):523-528.

12. van Vlerken LE, Vyas TK, Amiji MM. Poly(ethylene glycol)-modified nanocarriers for tumor-targeted and intracellular delivery. Pharm Res. 2007;24(8):1405-1414.

13. Sheng Y, Liu CS, Yuan Y, et al. Long-circulating polymeric nanoparticles bearing a combinatorial coating of PEG and water-soluble chitosan. Biomaterials. 2009;30(12):2340-2348.

14. Xie J, Xu C, Kohler N, Hou Y, Sun S. Controlled PEGylation of monodisperse $\mathrm{Fe}_{3} \mathrm{O}_{4}$ nanoparticles for reduced non-specific uptake by macrophage cells. Adv Mater. 2007;19(20):3163-3166.

15. Liu DF, Wu W, Ling JJ, Wen S, Gu N, Zhang XZ. Effective PEGylation of iron oxide nanoparticles for high performance in vivo cancer imaging. Adv Funct Mater. 2011;21(8):1498-1504.

16. Reimhult E, Amstad E, Gillich T, Bilecka I, Textor M. Ultrastable iron oxide nanoparticle colloidal suspensions using dispersants with catechol-derived anchor groups. Nano Lett. 2009;9(12): 4042-4048.

17. Huang X, Peng X, Wang Y, Shin DM, El-Sayed MA, Nie S. A reexamination of active and passive tumor targeting by using rod-shaped gold nanocrystals and covalently conjugated peptide ligands. ACS Nano. 2010;4(10):5887-5896.

18. Lee H, Lee E, Kim DK, Jang NK, Jeong YY, Jon S. Antibiofouling polymer-coated superparamagnetic iron oxide nanoparticles as potential magnetic resonance contrast agents for in vivo cancer imaging. $J \mathrm{Am}$ Chem Soc. 2006;128(22):7383-7389.

19. Lee H, Yu MK, Park S, et al. Thermally cross-linked superparamagnetic iron oxide nanoparticles: synthesis and application as a dual Imaging probe for cancer in vivo. J Am Chem Soc. 2007;129(42): 12739-12745.

20. Chen HW, Wu XY, Duan HW, et al. Biocompatible polysiloxanecontaining diblock copolymer PEO-b-P $\gamma$ MPS for coating magnetic nanoparticles. ACS Appl Mater Interfaces. 2009;1(10):2134-2140.

21. Chen HW, Wang LY, Yeh J, et al. Reducing non-specific binding and uptake of nanoparticles and improving cell targeting with an antifouling PEO-b-PgMPS copolymer coating. Biomaterials. 2010;31(20):5397-5407.

22. Yang LL, Mao H, Wang YA, et al. Single chain epidermal growth factor receptor antibody conjugated nanoparticles for in vivo tumor targeting and imaging. Small. 2009;5(2):235-243.

23. Yu WW, Falkner JC, Yavuz CT, Colvin VL. Synthesis of monodisperse iron oxide nanocrystals by thermal decomposition of iron carboxylate salts. Chem Commun (Camb). 2004(20):2306-2307.

24. Lee J, Choi Y, Kim K, et al. Characterization and cancer cell specific binding properties of anti-egfr antibody conjugated quantum dots. Bioconjug Chem. 2010;21(5):940-946.

25. Shukla R, Thomas TP, Desai AM, Kotlyar A, Park SJ, Baker JR. HER2 specific delivery of methotrexate by dendrimer conjugated antiHER2 mAb. Nanotechnology. 2008;19(29):295102.
26. Atkins RC. Colorimetric determination of iron in vitamin supplement tablets - general chemistry experiment. J Chem Educ. 1975; 52(8):550.

27. Bradford MM. Rapid and sensitive method for quantitation of microgram quantities of protein utilizing principle of protein-dye binding. Anal Biochem. 1976;72(1-2):248-254.

28. Jain TK, Reddy MK, Morales MA, Leslie-Pelecky DL, Labhasetwar V. Biodistribution, clearance, and biocompatibility of iron oxide magnetic nanoparticles in rats. Mol Pharm. 2008;5(2):316-327.

29. Yang L, Peng XH, Wang YA, et al. Receptor-targeted nanoparticles for in vivo imaging of breast cancer. Clin Cancer Res. 2009;15(14): $4722-4732$.

30. Bagwe RP, Hilliard LR, Tan WH. Surface modification of silica nanoparticles to reduce aggregation and nonspecific binding. Langmuir. 2006;22(9):4357-4362.

31. Kirpotin DB, Drummond DC, Shao Y, et al. Antibody targeting of long-circulating lipidic nanoparticles does not increase tumor localization but does increase internalization in animal models. Cancer Res. 2006;66(13):6732-6740.

32. McNeeley KM, Annapragada A, Bellamkonda RV. Decreased circulation time offsets increased efficacy of PEGylated nanocarriers targeting folate receptors of glioma. Nanotechnology. 2007;18(38):385101.

33. Wang X, Li J, Wang YQ, et al. HFT-T, a targeting nanoparticle enhances specific delivery of paclitaxel to folate receptor-positive tumors. ACS Nano. 2009;3(10):3165-3174.

34. Choi CHJ, Alabi CA, Webster P, Davis ME. Mechanism of active targeting in solid tumors with transferrin-containing gold nanoparticles. Proc Natl Acad Sci U S A. 2010;107(3):1235-1240.

35. Chen J, Saeki F, Wiley BJ, et al. Gold nanocages: bioconjugation and their potential use as optical imaging contrast agents. Nano Lett. 2005;5(3):473-477.

36. Shukla R, Thomas TP, Peters JL, et al. HER2 specific tumor targeting with dendrimer conjugated anti-HER2 mAb. Bioconjug Chem. 2006;17(5):1109-1115.

37. Gao X, Yezhelyev MV, Al-Hajj A, et al. In situ molecular profiling of breast cancer biomarkers with multicolor quantum dots. Adv Mater. 2007;19(20):3146-3151.

38. Anhorn MG, Wagner S, Kreuter J, Langer K, von Briesen H. Specific targeting of HER2 overexpressing breast cancer cells with doxorubicinloaded trastuzumab-modified human serum albumin nanoparticles. Bioconjug Chem. 2008;19(12):2321-2331.

39. Motamedi M, Eghtedari M, Liopo AV, Copland JA, Oraevslty AA. Engineering of hetero-functional gold nanorods for the in vivo molecular targeting of breast cancer cells. Nano Lett. 2009;9(1):287-291.

40. Colombo M, Corsi F, Foschi D, et al. HER2 targeting as a two-sided strategy for breast cancer diagnosis and treatment: outlook and recent implications in nanomedical approaches. Pharmacol Res. 2010; 62(2):150-165.

41. Suh JS, Lee JH, Huh YM, et al. Artificially engineered magnetic nanoparticles for ultra-sensitive molecular imaging. Nat Med. 2007;13(1): 95-99.

42. Neoh KG, Wuang SC, Kang ET, Pack DW, Leckband DE. HER-2mediated endocytosis of magnetic nanospheres and the implications in cell targeting and particle magnetization. Biomaterials. 2008;29(14):2270-2279.

43. Yang HM, Park CW, Woo MA, et al. HER2/neu antibody conjugated poly(amino acid)-coated iron oxide nanoparticles for breast cancer MR Imaging. Biomacromolecules. 2010;11(11):2866-2872.

44. Xu CJ, Wang BD, Sun SH. Dumbbell-like $\mathrm{Au}-\mathrm{Fe}_{3} \mathrm{O}_{4}$ nanoparticles for target-specific platin delivery. J Am Chem Soc. 2009;131(12):4216-4217.

45. Peng XH, Qian X, Mao H, et al. Targeted magnetic iron oxide nanoparticles for tumor imaging and therapy. Int J Nanomedicine. 2008;3(3):311-321.

46. Zhang CF, Jugold M, Woenne EC, et al. Specific targeting of tumor angiogenesis by RGD-conjugated ultrasmall superparamagnetic iron oxide particles using a clinical 1.5-T magnetic resonance scanner. Cancer Res. 2007;67(4):1555-1562. 
47. Lee MJE, Veiseh O, Bhattarai N, et al. Rapid pharmacokinetic and biodistribution studies using cholorotoxin-conjugated iron oxide nanoparticles: a novel non-radioactive method. PLoS One. 2010;5(3):e9536.

48. Mitruka BM, Rawnsley HM. Clinical, Biochemical and Hematological Reference Values in Normal Experimental Animals and Normal Humans. New York, NY: Masson Publishing; 1981.

49. Chou SW, Shau YH, Wu PC, Yang YS, Shieh DB, Chen CC. In vitro and in vivo studies of FePt nanoparticles for dual modal CT/MRI molecular imaging. J Am Chem Soc. 2010;132(38):13270-13278.
50. Sinha R, Kim GJ, Nie SM, Shin DM. Nanotechnology in cancer therapeutics: bioconjugated nanoparticles for drug delivery. Mol Cancer Ther. 2006;5(8):1909-1917.

51. Jain RK. Transport of molecules, particles, and cells in solid tumors. Annu Rev Biomed Eng. 1999;1:241-263. 


\section{Supplementary materials}

Iron concentrations in mouse blood and organs as well as in iron oxide nanoparticle solution were determined colorimetrically using 1,10 -phenanthroline. ${ }^{1} \mathrm{~A}$ calibration curve was created using standard solutions containing the iron-1,10phenanthroline compound in water with iron concentrations ranging from $0.4 \mu \mathrm{g} / \mathrm{mL}$ to $4 \mu \mathrm{g} / \mathrm{mL}$.

\section{Reagents}

The reagents used were hydroquinone $10 \mathrm{~g} / \mathrm{L}$ in water; o-phenanthroline $2.5 \mathrm{~g}$ in $100 \mathrm{~mL}$ of ethanol and $900 \mathrm{~mL}$ of water; trisodium citrate $50 \mathrm{~g} / \mathrm{L}$ in water; standard Fe solution $0.281 \mathrm{~g}$ of $\mathrm{Fe}\left(\mathrm{NH}_{4}\right)_{2}\left(\mathrm{SO}_{4}\right)_{2} \cdot 6 \mathrm{H}_{2} \mathrm{O}$ in a $1,000 \mathrm{~mL}$ flask with $1 \mathrm{~mL}$ of $98 \mathrm{wt} \% \mathrm{H}_{2} \mathrm{SO}_{4}$; standard solution is $0.04 \mathrm{mg}$ $\mathrm{Fe} / \mathrm{mL}$.

\section{Standards}

1. Five dilutions from standard solution $(0.04 \mathrm{mg} \mathrm{Fe} / \mathrm{mL})$ : $10 \mathrm{~mL}, 5 \mathrm{~mL}, 2 \mathrm{~mL}$, and $1 \mathrm{~mL}$ of standard solution, and one non-Fe control solution (eventually diluted to $100 \mathrm{~mL}$ )

2. All solutions are adjusted to $\mathrm{pH} 3.5$ with sodium citrate solution

3. Add $2 \mathrm{~mL}$ of hydroquinone and $3 \mathrm{~mL}$ of o-phenanthroline to each solution and dilute to $100 \mathrm{~mL}$ with water; wait 2 hours before measuring it; the solution is stable for over a year

4. Measure absorbance for each solution at $508 \mathrm{~nm}$ and make graph of $\left[\mathrm{Fe}^{2+}\right]$ versus absorbance.

\section{Measurement of Fe concentrations}

in iron oxide nanoparticle solution

1. Take $10-50 \mu \mathrm{L}$ of iron oxide nanoparticles $(1-5 \mathrm{mg} / \mathrm{mL})$ stock solution

2. Adjust $\mathrm{pH}$ to 3.5 using sodium citrate

3. Add $2 \mathrm{~mL}$ of hydroquinone and $3 \mathrm{~mL}$ of o-phenanthroline to each solution and dilute to the specific volume with water; wait 2 hours before measuring it; the solution is stable for over one year

4. Measure absorbance for each solution at $508 \mathrm{~nm}$ and compare absorbance with those of standard $\mathrm{Fe}$ solutions.

\section{Measure Fe concentrations in serum and organ tissue samples}

Blood was collected by terminal heart puncture and centrifuged for 10 minutes at 5,000 rpm to separate the serum $(100 \mu \mathrm{L})$. Mouse organs were freeze-dried for 2 days. The organs were weighed before decomposition. Next, $1 \mathrm{~mL}$ of concentrated nitric acid was added to each sample ( $2 \mathrm{~mL}$ for liver) in a $15 \mathrm{~mL}$ centrifuge tube for 3 days. After filtration using a syringe filter (Catalog number $6782-1302), 200 \mu \mathrm{L}$ of decomposed solution $(400 \mu \mathrm{L}$ of serum) was used to measure the iron, repeating steps 2-5 shown above. These solutions are not stable for a long time. Wait 2 hours and record the absorption as soon as possible (not overnight).
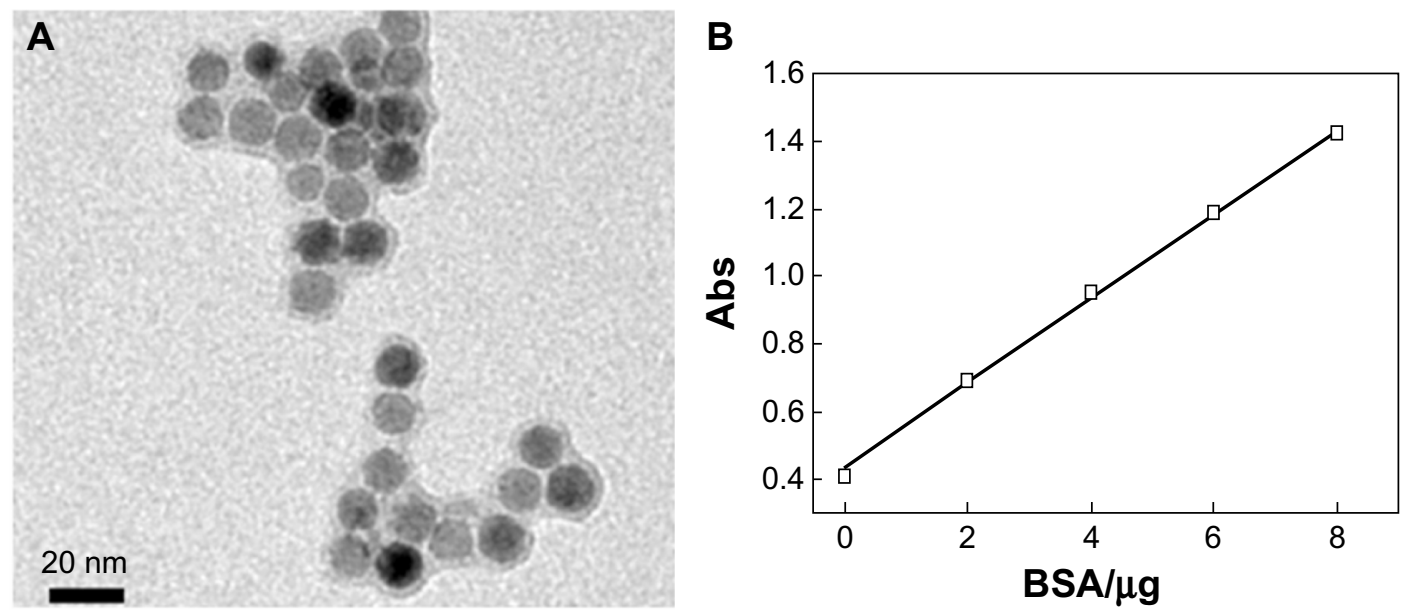

Figure SI (A) Transmission electronic microscopic image of iron oxide nanoparticles conjugated with single chain fragment of antibody against epidermal growth factor receptor. (B) Calibration curve for measuring protein concentrations based on the Bradford protocol.

Abbreviations: Abs, absorbance (arbitrary unit); BSA, bovine serum albumin. 


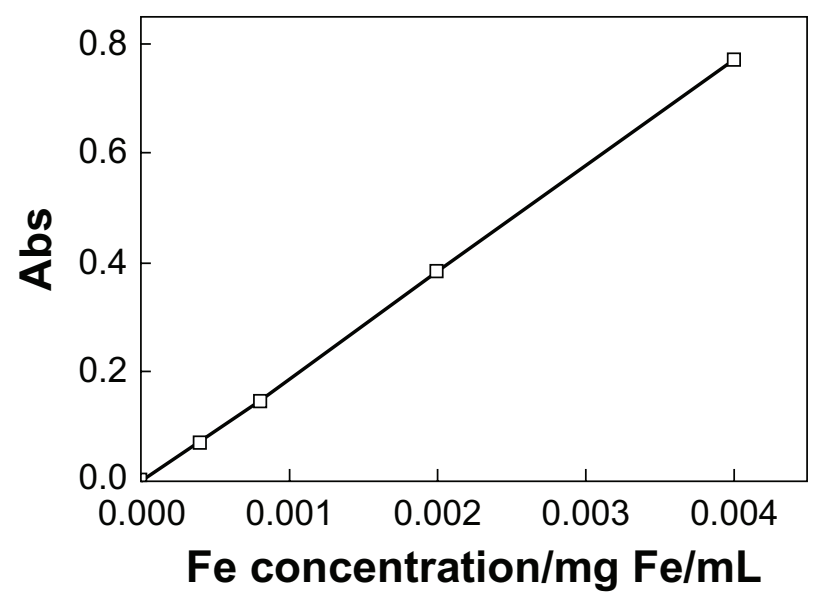

Figure S2 Calibration curve for determination of iron concentration colorimetrically using I, I0-phenanthroline.

Abbreviation: Abs, absorbance (arbitrary unit).

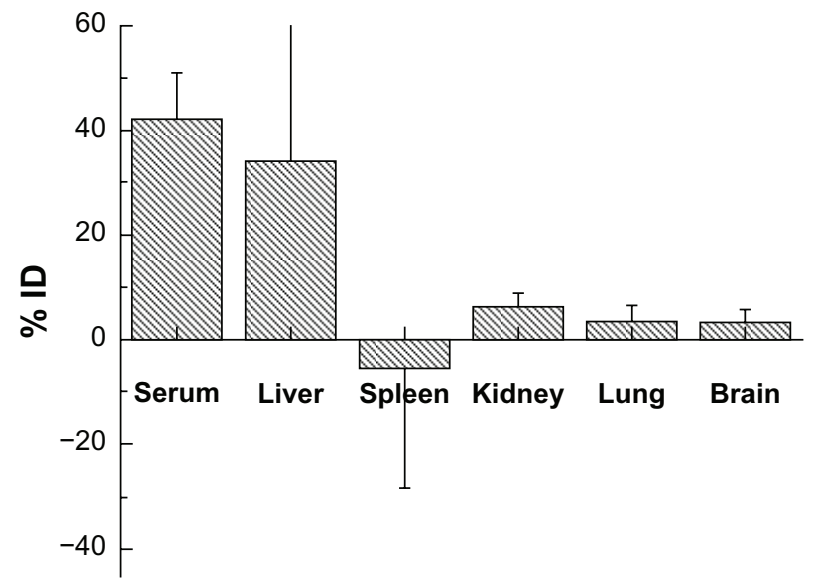

Figure S3 Percentages of the injection dose in mice serum and main organs at 24 hours post injection of PEO-b-PyMPS-coated IONPs. The values shown here have been subtracted with the averaged background iron concentrations obtained from control mice. It should be noted that the negative \% ID value in spleen is likely due to the fact that the accumulation of administered PEO-b-PYMPS diblock copolymer-coated IONPs in spleen is so low that it is within the variation from the spleen iron concentration averaged from different animals. The large variation of iron concentration in the spleen as well as liver measured by chemical analysis of tissue samples can be attributed to the significantly higher basal iron concentrations in the liver and spleen (eg, $6.8 \pm 1.0 \mathrm{mg} \mathrm{Fe} / \mathrm{g}$ dry tissue).

Abbreviations: ID, injection dose; IONPs, iron oxide nanoparticles; PEO-b-PyMPS, poly(ethylene oxide)-block-poly( $\gamma$-methacryloxypropyltrimethoxysilane).

\section{Reference}

1. Atkins RC. Colorimetric determination of iron in vitamin supplement tablets - a general chemistry experiment. J Chem Educ. 1975;52:550.

\section{Publish your work in this journal}

The International Journal of Nanomedicine is an international, peerreviewed journal focusing on the application of nanotechnology in diagnostics, therapeutics, and drug delivery systems throughout the biomedical field. This journal is indexed on PubMed Central, MedLine, CAS, SciSearch ${ }^{\circledR}$, Current Contents $® /$ Clinical Medicine,
Journal Citation Reports/Science Edition, EMBase, Scopus and the Elsevier Bibliographic databases. The manuscript management system is completely online and includes a very quick and fair peer-review system, which is all easy to use. Visit http://www.dovepress.com/ testimonials.php to read real quotes from published authors. 